\title{
EXPERIÊNCIA EXTENSIONISTA NA PRIMEIRA SEMANA DE DIREITOS HUMANOS DA UFSC (22 A 26 DE NOVEMBRO DE 2010)
}

Originais recebidos em: 12/06/011

Aceito para publicação em: 08/09/2011

Danielle Annoni

Universidade Federal de Santa Catarina danielle.annoni@gmail.com

Felipe Orsolin Muller

Universidade Federal de Santa Catarina felipeom@live.com

\section{Resumo}

O presente trabalho tem como objetivo expor a experiência extensionista no projeto Primeira Semana de Direitos Humanos da Universidade Federal de Santa Catarina (UFSC), realizada entre os dias 22 a 26 de novembro de 2010. As atividades de extensão iniciaram-se no mês de junho de 2010 e prologaram-se até o mês de maio do próximo ano, com a publicação dos resultados através dos Anais da Primeira Semana de Direitos Humanos da UFSC. Por ter sido a primeira edição do projeto, o trabalho abordará, sobretudo, as ferramentas e desafios para a implantação deste e o impacto na comunidade universitária e nos arredores do campus Florianópolis-SC.
Palavras-chave: Direitos Humanos. OEA. Semana de Direitos Humanos. Convenção Americana de Direitos Humanos.

\section{EXPERIENCE IN THE HUMAN RIGHTS \\ FIRST WEEK - Federal University of \\ Santa Catarina (UFSC) - 22 TO 26 \\ NOVEMBER 2010}

Keywords: Human Rights. AEO. Human Rights Week. American Convention on Human Rights. 


\section{INTRODUÇÃO}

A $1^{\text {a }}$ Semana de Direitos Humanos da Universidade Federal de Santa Catarina (UFSC) foi um projeto de extensão coordenado pela professora Danielle Annoni (Centro de Ciências Jurídicas - CCJ) em parceria com graduandos do curso de Relações Internacionais. O evento aconteceu entre os dias 22 e 26 de novembro de 2010, sendo composto por uma programação diversificada, com mesas de discussão, atrações artísticas e culturais, concurso de redação, palestras, cinema e minicurso.

A proposição foi integrar os grupos de pesquisa em direitos humanos dos programas de pós-graduação dos diversos cursos da UFSC, possibilitando uma interação entre a comunidade universitária através de debates e reflexões fomentados por estes grupos. O projeto visou integralizar os movimentos sociais locais e regionais aos grupos de pesquisa cujas temáticas fossem pertinentes e despertar, durante o evento, a comunidade universitária e a sociedade civil para pensar na promoção e efetivação dos direitos humanos, fomentando o pensar em soluções compartilhadas, tanto em um contexto regional quanto nacional, com a possibilidade de reflexão acerca da efetivação dos direitos humanos, em seus mais diversos âmbitos.

A preocupação primordial do projeto foi ressaltar a presença dos direitos humanos em diversas perspectivas, como as atividades artísticas, culturais, lúdicas, acadêmicas e também de lazer, além de promover, por estes diversos meios, a educação e a conscientização para os direitos humanos, considerados aqui como direitos de todos os seres humanos, sem distinção de características físicas ou psicológicas, religião, sexo, cultura, faixa etária, situação social ou econômica, formação profissional ou intelectual, e a universidade deve ser o espaço de reunião destas muitas diferenças que simbolizam a riqueza cultural e humana da nossa sociedade.

Em 2010 o tema abordado foi o aniversário da Convenção Americana de Direitos Humanos, ou Pacto de San José da Costa Rica, que agrupa diversas categorias de direitos humanos reconhecidos internacionalmente e que devem ser respeitados e efetivados por todos os Estados americanos, dentre os quais o Brasil, ${ }^{1}$ que tem o tema como importante assunto em sua agenda internacional.

\footnotetext{
1 O país ratificou a Convenção Americana de Direitos Humanos no ano de 1992, sendo este instrumento considerado um dos mais importantes mecanismos de proteção aos direitos humanos em âmbito internacional.
} 
Internacionalmente, a Semana de Direitos Humanos foi desenvolvida originalmente pela Organização das Nações Unidas (ONU) com objetivo de desenvolver o debate sobre a efetivação de direitos humanos durante o período em que se celebra a ratificação da Declaração Universal. Na Europa, o evento pretende comemorar a ratificação da Convenção Europeia de Direitos Humanos, enquanto no âmbito americano a Semana visa comemorar a Convenção Americana de Direitos Humanos. No presente artigo, falaremos de modo geral a respeito da Convenção, tema da primeira Semana de Direitos Humanos da UFSC, e dos objetivos, resultados e atividades realizadas durante a execução do projeto.

\subsection{A Convenção Americana de Direitos Humanos}

A Convenção Americana de Direitos Humanos é um marco de proteção aos direitos humanos no Brasil. Muito já se falou sobre este instrumento jurídico de proteção, e ainda hoje muitas são as discussões em torno de sua influência e eficácia no âmbito americano. Criado como um tratado internacional da Organização dos Estados Americanos (OEA), o Pacto de San Jose da Costa Rica, como ficou conhecido, foi além de um instrumento internacional de fomento à promoção dos direitos humanos entre os povos da América: deu origem a um sistema jurídico internacional de salvaguarda dos direitos humanos no continente americano. (ANNONI, 2006)

Tal sistema, conhecido como sistema interamericano, é formado por uma Comissão de Direitos Humanos e também por uma Corte de Justiça, chamada Corte Interamericana de Direitos Humanos. A Comissão tem a função principal de receber as denúncias de violação aos direitos humanos, ouvir as testemunhas, organizar o caso e levá-lo para ser julgado perante a Corte. A Corte, por sua vez, tem a função principal de julgar as denuncias contra os Estados pela violação dos direitos preconizados na Convenção, atribuindo aos Estados punições internacionais, que vão desde o pagamento de indenizações até a mudança na legislação interna, visando coibir que a violação de tal direito se repita. (ANNONI, 2002)

O sistema interamericano, criado a partir da Convenção Americana de Direitos Humanos atua como órgão jurisdicional subsidiário, defendendo as vítimas de violação de direitos humanos quando seus próprios Estados, a partir do Poder Judiciário, não foram capazes de fazê-lo adequadamente. (FOLMANN; ANNONI, 2006)

A Convenção Americana de Direitos Humanos, dentre seus inúmeros artigos, protege os direitos civis, políticos, sociais, econômicos e culturais, deixando claro que toda forma de 
salvaguarda do ser humano deve ser tutelada pelo Estado. Assim, não há distinção entre direitos civis, como a vida, integridade física e liberdade; dos direitos sociais, como saúde e educação, segurança e trabalho; e, ainda, dos direitos culturais, de acesso à cultura, manifestação artística, preservação das tradições. O Estado deve proteger todos estes direitos, de igual modo, garantindo para todos o mesmo acesso a eles. Um Estado não pode alegar carência de recursos econômicos para deixar de promover um determinado direito de uma determinada minoria. Todos os direitos, incluindo o direito ao lazer, são direitos humanos. (ANNONI, 2004)

Com esta mensagem, a Primeira Semana de Direitos Humanos procurou reunir as mais diversas formas de expressão, visando demonstrar que todos os direitos, de todas as pessoas, e suas mais diversas manifestações, são protegidos pela Convenção Americana de Direitos Humanos e também pelo Brasil.

O evento proposto como atividade de extensão caracteriza-se pela possibilidade de integrar alunos e pesquisadores em torno de um tema tão importante como a promoção e divulgação dos mais diversos direitos humanos. A escolha do tema não se deu por acaso. Como visto, a Convenção Americana de Direitos Humanos é um dos mais importantes instrumentos de promoção dos direitos humanos nas Américas, sendo referência obrigatória aos estudiosos do tema no continente americano. Falar em direitos humanos no Brasil implica, pois, reconstituir a história da promoção dos direitos humanos no país, em especial, após a reabertura democrática, e, portanto, o Pacto de San Jose da Costa Rica surge como um dos mais valorosos e importantes instrumentos de seu fomento e proteção.

No presente trabalho pretende-se, pois, ressaltar a importância da Convenção Americana de Direitos Humanos, descrevendo como as atividades realizadas na Primeira Semana de Direitos Humanos contribuíram para sua promoção e também para a integração dos mais distintos grupos de pesquisa e pessoas, mobilizados em prol de uma mesma causa: fomentar o debate constante em torno da salvaguarda dos direitos de todos.

\section{MATERIAL E MÉTODOS}

O início das atividades de extensão aconteceu no decorrer do mês de junho de 2010, quando foram realizadas diversas reuniões de planejamento da Semana e seus respectivos eventos. Foram definidos temas, distribuídos entre a coordenação e a equipe executiva, 
composta por dois bolsistas e um voluntário. Estes ficaram alocados em três distintas comissões: acadêmica, lúdica e de cidadania.

No primeiro mês de trabalho, as reuniões eram semanais e tinham a função de reunir ideias para a confecção do projeto definitivo, substancial para a submissão deste aos principais órgãos de fomento, como a Coordenação de Aperfeiçoamento de Pessoal de Nível Superior (CAPES) e o Conselho Nacional de Desenvolvimento Científico e Tecnológico.

\subsection{Segundo mês (15/07/2010-15/08/2010) - Planejamento, pesquisa e primeiros contatos.}

Dar início a um projeto na universidade com tímidos recursos, embora com um objetivo audacioso de integração comunitária-acadêmica acerca do debate sobre direitos humanos, é uma atividade naturalmente desafiadora. Com a aprovação do projeto de extensão e a inclusão de apenas dois bolsistas para desempenharem as atividades propostas, além de uma voluntária do curso de graduação em Relações Internacionais, nada mais sensato que procurar por voluntários, seja em âmbito de graduação, mestrado, ou ainda entre professores e profissionais de organizações internacionais. Após pensarmos a estrutura básica do evento, que deveria incluir atividades acadêmicas, lúdicas e de cidadania, foi debatida a logística para a sua concretização (demanda de estrutura física e humana), bem como a solicitação de apoio financeiro por parte de institutos como CAPES, CNPq e UFSC. As primeiras atividades desempenhadas foram o desenvolvimento de um blog, um grupo de e-mails e, posteriormente, um site para que obtivéssemos um bom resultado comunicativo entre o grupo e os potenciais participantes do evento. Como ponte de partida, foi definida uma agenda pretendida, composta especificamente por ações de cidadania (campanha para doação de sangue e doação de livros), cinema e teatro, exposição de cartazes, oficinas e palestras. Esta agenda deveria ocupar os cinco dias da semana, de 22 a 26 de novembro de 2010, em vista do aniversário da Convenção Americana de Direitos Humanos, de 22 de novembro de 1969.

Após a definição da agenda, demanda de estrutura e datas, foram realizados os primeiros contatos com a direção dos centros de ensino da universidade, na busca por disponibilidade de espaço físico. Também foram procurados profissionais de organizações internacionais como a Organização dos Estados Americanos (OEA), Organização das Nações Unidas (ONU), Comitê Internacional da Cruz Vermelha (ICRC), Serviço Voluntário Internacional (SVI). Estes profissionais eram pretendidos para a participação em palestras, 
minicursos e oficinas. Paralelo a isso, foi desenvolvida uma ampla pesquisa em torno dos grupos de estudos em Direitos Humanos da UFSC e seus diversos centros de ensino e cursos de graduação e pós-graduação.

Especificamente, a agenda de tarefas desempenhada foi: reserva do hall da reitoria universitária, dos halls, auditórios e salas dos centros de ensino e reserva do espaço audiovisual da Biblioteca Universitária. Ao mesmo tempo, foi realizado contato com o professor Christian Courtis, alto comissariado das Nações Unidas para os Direitos Humanos e com a OEA, com contatos localizados através de mecanismos de pesquisa on-line, sítios de organizações não governamentais, institutos e universidades. Assim, convites foram enviados a diversos professores, profissionais e instituições, em busca de apoio e contribuição para a efetiva realização do projeto.

\subsection{Terceiro mês $(15 / 08 / 2010-15 / 09 / 2010)$}

Em resposta aos convites feitos durante os primeiros quinze dias das atividades, o projeto conseguiu atrair seis voluntários, todos do curso de graduação de Relações Internacionais da UFSC. Com uma equipe maior, a Semana manteve a mesma forma, porém aumentou sua pretensão de alcance de público e número de atividades. Devido às respostas negativas dos institutos procurados para concessão de apoio financeiro, buscou-se contatar departamentos da UFSC, como a direção do Centro Sócio-Econômico, a Pró-Reitoria de Pesquisa e Extensão (PRPE) e também o Programa de Pós-Graduação em Direito da UFSC (PPGD). Nestas instâncias, obtivemos respostas financeiras positivas que puderam garantir a realização da Conferência de Abertura, após confirmação da vinda voluntária do professor Christian Courtis, secretário do Alto Comissariado da ONU para os Direitos Humanos.

Quanto à identidade visual do evento, foi realizado um estudo de cores, ou "cromoterapia", para definição da logomarca e demais aspectos de divulgação. Na parte de comunicação foi criado o domínio www.direitoshumanos.ufsc.br e páginas em portais de relacionamento como o Twitter e Facebook. ${ }^{2}$

\subsection{Quarto Mês (15/09/2010-15/10/2010)}

\footnotetext{
${ }^{2}$ No microblog Twitter, o endereço do projeto é: www.twitter.com/dhufsc. Na rede social Facebook, o domínio é intitulado "direitos humanos": www.facebook.com/direitoshumanos.
} 
Neste período foram realizados os ajustes finais na programação da Semana, que ficou organizada como nos mostra o Quadro 1.

\begin{tabular}{|c|c|c|c|c|c|}
\hline & $\begin{array}{l}\text { SEGUNDA } \\
22 / 11\end{array}$ & $\begin{array}{l}\text { TERÇA } \\
\text { 23/11 }\end{array}$ & $\begin{array}{l}\text { QUARTA } \\
24 / 11\end{array}$ & $\begin{array}{l}\text { QUINTA } \\
25 / 11\end{array}$ & $\begin{array}{l}\text { SEXTA } \\
26 / 11\end{array}$ \\
\hline Manhã & & $\begin{array}{l}\text { Oficina de } \\
\text { Tango } \\
1 \\
\text { Local: Sala } \\
\text { de Ginástica } \\
\text { Ed. Física } \\
\text { UFSC } \\
\text { Horário: } \\
10 \mathrm{~h} 30 \text { às } 12 \mathrm{~h}\end{array}$ & $\begin{array}{l}\text { Oficina } 1 \\
\text { Infầncia e } \\
\text { Violência } \\
\text { Local: Sala } \\
109 \text { CCJ } \\
\text { Horário: } 10 \mathrm{~h} \\
\text { às } 12 \mathrm{~h}\end{array}$ & $\begin{array}{l}\text { Parceria } \\
\text { Projeto CINE } \\
\text { RI } \\
\text { "Hotel } \\
\text { Ruanda" } \\
\text { Local: } \\
\text { Miniauditório } \\
\text { de Economia } \\
\text { CSE } \\
\text { Horário: 10h }\end{array}$ & $\begin{array}{l}\text { Oficina de } \\
\text { Tango } 2 \\
\text { Local: Sala de } \\
\text { Ginástica Ed. } \\
\text { Física UFSC } \\
\text { Horário: } 10 \mathrm{~h} 30 \\
\text { às } 12 \mathrm{~h}\end{array}$ \\
\hline
\end{tabular}

\section{Meio-dia}

Tarde

Show Banda
de
Rock "Al
Pacinos"
Local:
Concha
Horário:
12h30

\section{Show Banda}

de

Rock "Al

Pacinos"

Local:

Horário:

$12 \mathrm{~h} 30$
Cinema BU

Concurso de

Redação

Local: Auditório

BU

Horário: $15 \mathrm{~h}$

\begin{tabular}{|c|c|c|c|}
\hline 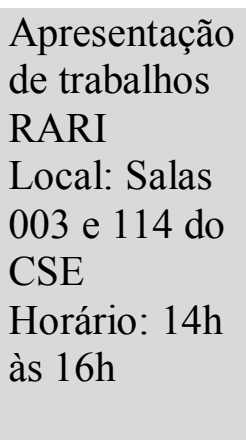 & $\begin{array}{l}\text { Exposição } \\
\text { Vietnã } \\
\text { Local: Hall da } \\
\text { Reitoria } \\
\text { Horário: } 14 \mathrm{~h} \\
\text { às } 17 \mathrm{~h} 30\end{array}$ & $\begin{array}{l}\text { Minicurso } \\
\text { Voluntariado } \\
\text { Internacional } \\
\text { (SVI) } \\
\text { Horário: } \\
16 \text { h30 às } \\
18 \text { h30 } \\
\text { Sala: } 003 \text { do } \\
\text { CSE }\end{array}$ & $\begin{array}{l}\text { Oficina } 2 \\
\text { Cidadania e } \\
\text { Exclusão } \\
\text { Local: sala } 114 \\
\text { CSE } \\
\text { Horário: } 15 \mathrm{~h} \text { às } \\
17 \mathrm{~h}\end{array}$ \\
\hline
\end{tabular}

\begin{tabular}{|c|c|c|c|c|c|}
\hline Noite & $\begin{array}{l}\text { Conferência } \\
\text { de Abertura } \\
\text { Christian } \\
\text { Courtis } \\
\text { Local: } \\
\text { Auditório } \\
\text { do CCJ } \\
\text { Horário: } \\
\text { 19h30 }\end{array}$ & $\begin{array}{l}\text { Exposição } \\
\text { Cruz } \\
\text { Vermelha } \\
\text { Local: Hall } \\
\text { do CFH } \\
\text { Horário: } \\
\text { 19h30 às } \\
20 \mathrm{~h} 30\end{array}$ & $\begin{array}{l}\text { Dança Afro } \\
\text { Local: Concha } \\
\text { Acústica } \\
\text { Horário: } 18 \mathrm{~h} \\
\text {-- } \\
\text { Palestra } \\
\text { Magna } \\
\text { Marco Antônio } \\
\text { Vieira } \\
\text { Local: } \\
\text { Auditório da } \\
\text { Reitoria } \\
\text { Universitária }\end{array}$ & $\begin{array}{l}\text { Exposição } \\
\text { Cruz } \\
\text { Vermelha } \\
\text { Local: Hall } \\
\text { do CSE } \\
\text { Horário: } \\
\text { 19h30 às } \\
20 \mathrm{~h} 30\end{array}$ & $\begin{array}{l}\text { Confraternização } \\
\text { de encerramento }\end{array}$ \\
\hline
\end{tabular}




\section{Horário: $19 \mathrm{~h} 30$}

Quadro 1 - Programação da Primeira Semana de Direitos Humanos da UFSC

Fonte: elaboração própria

\subsection{Quinto Mês (15/10/2010-22/11/2010)}

Com a programação ajustada e todas as atividades confirmadas, durante o mês de outubro e novembro o foco foi direcionado à divulgação do evento através do sítio oficial e das redes sociais na Internet e à preparação e distribuição dos flyers, cartazes e banners. Também foi feito contato com a Agência de Comunicação da UFSC (AGECOM), que divulgou a Semana para a comunidade universitária. Nesta etapa, as ferramentas de comunicação on-line foram de suma importância, e a Semana de Direitos Humanos conseguiu alastrar-se pela Internet através de blogs, como o Portal do Voluntário, além do mailing de emails disponibilizado pela própria Universidade.

Tanto na criação quanto na distribuição do material gráfico, cuidou-se para que a Semana pudesse atingir um público diversificado, fazendo todos os centros de ensino da UFSC pensarem acerca dos Direitos Humanos e da Convenção Americana para o tema. Como desafios, o relacionamento com profissionais de empresas privadas (gráficas e criação visual) podem ser destacados. De modo geral, a Internet possibilitou um impacto acima do esperado na comunidade universitária. Na verdade, a equipe do projeto apostou em ferramentas inovadoras desde o início, como meio de suprir a carência de recursos financeiros. O resultado foi muito satisfatório e garantiu fôlego aos bolsistas e voluntários, que puderam continuar trabalhando com o retorno imediato do público, sobretudo nas duas semanas que antecederam o evento.

\section{A PRIMEIRA SEMANA DE DIREITOS HUMANOS DA UFSC: DE 22 A 26 DE NOVEMBRO DE 2010}

No decorrer dos cinco dias de atividades da Semana de Direitos Humanos, inúmeros imprevistos foram constatados: condições climáticas, atrasos de voos, problema para o uso efetivo de espaços reservados na universidade e de equipamentos de áudio e microfonia, pouca participação do público em atividades específicas, como o concurso de redação, etc. De modo geral, os desafios foram todos superados com criatividade, bom humor e muita responsabilidade. Após o cumprimento da agenda diária, que se estendia pelos três turnos, a 
equipe se reunia em sala localizada no Centro de Ciências Jurídicas (CCJ/UFSC) para debater e comemorar juntos os resultados das atividades de extensão.

\section{APRENDIZADO DESENVOLVIDO}

Ao longo do projeto inúmeras competências pessoais e profissionais puderam ser desenvolvidas: o planejamento das atividades, juntamente com o curso de graduação em Relações Internacionais, permitiu contato com organizações internacionais, como a Organização das Nações Unidas (ONU) e Organização dos Estados Americanos (OEA), organizações não governamentais (Serviço Voluntário Internacional, Instituto Voluntários em Ação e o Instituto Promoción Estudios Sociales Elkartea - Espanha), empresas privadas e órgãos públicos (Projeto Marco Brasil, Fundação Padre Anchieta, empresas do setor gráfico) e com inúmeros profissionais da universidade, como técnicos e professores, além de participantes de outras instituições de ensino superior. O projeto contribuiu de modo positivo no desempenho acadêmico durante os dois semestres em que a atividade foi realizada.

Pode-se afirmar que a participação como bolsista de extensão na Semana de Direitos Humanos da UFSC foi uma experiência que possibilitou maior integração, convívio e envolvimento com a rotina agitada do campus universitário de Florianópolis. O conhecimento prático da realização de um evento em uma instituição de grande porte, como a Universidade Federal de Santa Catarina, facilita o desempenho acadêmico e profissional dos alunos envolvidos, ao passo que contribuiu para a disseminação dos direitos humanos no âmbito da comunidade universitária e da população civil como um todo.

\section{RESULTADOS E ANÁLISES}

Se inicialmente o projeto tinha como objetivo abrir espaços para a reflexão e discussão dos Direitos Humanos na comunidade acadêmica e também na sociedade, acabou desempenhando um papel ainda maior, que foi a interação e o trabalho em equipe visando à organização de um evento com retorno de público e considerado um grande sucesso. Quanto às dificuldades, destacam-se as burocracias dentro do ambiente da Universidade Federal e demais institutos e órgãos de financiamento. $\mathrm{O}$ fato de ser a primeira edição do projeto ampliou todos os desafios, principalmente a dificuldade de conseguir lidar com a dimensão do evento, à medida que este foi se desenvolvendo e crescendo graças ao trabalho da equipe. 
Neste aspecto, dois pontos podem ser ressaltados: na UFSC foi difícil garantir a reserva de espaços (muitas vezes ociosos) e apoio financeiro e operacional, fazendo com que a equipe tivesse de atuar de modo persuasivo para que reservas e concessões de apoio pudessem ser concretizadas. Outro obstáculo foi o relacionamento com profissionais de empresas privadas, como das gráficas contratadas para a confecção do material e impressão destes; por diversos momentos a equipe executou trabalhos que, a princípio, seriam terceirizados.

Os desafios foram superados com dedicação dos bolsistas e voluntários, além da coordenação da Semana, que incentivou a proatividade e respeito mútuo. Através de ferramentas de comunicação eficazes e reuniões periódicas conseguimos aperfeiçoar e otimizar o trabalho do grupo, suprindo as carências de recursos e dificuldades burocráticas como um todo.

\subsection{Os Anais do Evento}

Após o planejamento e execução das atividades, os bolsistas do projeto ficaram responsáveis por organizar uma publicação, intitulada Anais da Primeira Semana de Direitos Humanos da UFSC, que engloba relatórios, artigos científicos, entrevistas e depoimentos acerca da primeira edição o evento. Os resultados mais específicos do projeto e o trabalho como um todo podem ser conferidos a partir desta produção, que será publicada na conferência de abertura da Segunda Semana de Direitos Humanos, em 24 de outubro de 2011.

\subsection{O retorno do público}

Em praticamente todas as atividades realizadas, o retorno do público foi além ou dentro do esperado. Com destaque para a conferência de abertura, que lotou o auditório do Centro de Ciências Jurídicas (CCJ UFSC), e ao minicurso realizado em parceria com a organização não governamental Serviço Voluntário Internacional (SVI Brasil).

Um dos objetivos principais da Semana era o de integrar os diferentes grupos de estudos em torno dos Direitos Humanos na UFSC e demais instituições de ensino superior, além de envolver as comunidades do entorno e universitários de todas as áreas do conhecimento. Como resultado disto, na lista de frequência pode-se constatar a participação de alunos dos cursos de Relações Internacionais, Ciências Biológicas, Psicologia, Serviço Social, Direito, História e Economia, sobretudo de graduação, além de inúmeros professores, pós-graduandos e servidores da UFSC. 


\section{CONSIDERAÇÕES FINAIS}

Reunir profissionais distintos, acadêmicos e população civil, em torno de um mesmo tema tão complexo é uma tarefa naturalmente desafiadora e que exige grande ousadia ao ser projetada. Este foi justamente o principal objetivo da Primeira Semana de Direitos Humanos da UFSC, que comemorou o aniversário da Convenção Americana de Direitos Humanos. Em termos gerais, o objetivo do trabalho foi cumprido, a presença do público foi expressiva, qualificada e diversificada, o que confere um caráter heterogêneo ao projeto. Estudantes, pesquisadores, professores de graduação e pós-graduação, além de servidores da UFSC, membros de ONGs e Organizações Internacionais, puderam fazer parte da primeira edição de um evento que pretende se consolidar na universidade em torno de uma temática cada vez mais importante, ainda que possua espaços para discussão em nosso país, que engloba o tema em sua agenda internacional de política externa há vários anos. ${ }^{3}$

\section{REFERÊNCIAS}

ANNONI, Danielle. Direitos Humanos e Acesso à Justiça no Direito Internacional. Curitiba: Juruá, 2002.

Direitos Humanos e Poder Econômico: Conflitos e Alianças. Curitiba: Juruá, 2004. . O direito humano de acesso à justiça no Brasil. Porto Alegre: Safe, 2006.

(Org.). Os novos direitos do novo direito internacional: democracia, cidadania e direitos humanos. Rio de Janeiro: América Jurídica, 2002.

CARVALHO, Júlio Marino. Os Direitos Humanos no Tempo e no Espaço. Brasília: Brasília Jurídica, 1998.

FOLMANN, Melissa. ANNONI, Danielle (Org.). Direitos Humanos. Os 60 anos da Declaração Universa da ONU. Curitiba: Jurua, 2006.

OEA. Organização dos Estados Americanos. Disponível em: www.oas.org/pt/default.asp.. Acesso em: 25 maio 2011.

\footnotetext{
${ }^{3}$ De acordo com o Ministério das Relações Exteriores (MRE), "Ação contra a Fome e Assistência Humanitária" e "Direitos Humanos e Temas Sociais" são temas da atual Agenda Internacional do Brasil.
} 
ONU. Organização das Nações Unidas. Disponível em: $<$ http://www.onubrasil.org.br/>. Acesso em: 23 maio 2011. 